\title{
Effect of Smoking on Body Weight: Longitudinal Analysis of the SUN Cohort
}

\author{
F. Javier Basterra-Gortari, ${ }^{\mathrm{a}, \mathrm{b}}$ Lluis Forga, ${ }^{\mathrm{b}, \mathrm{c}}$ Maira Bes-Rastrollo, ${ }^{\mathrm{a}}$ Estefanía Toledo, ${ }^{\mathrm{a}, \mathrm{d}}$ \\ J. Alfredo Martínez, ${ }^{c}$ and Miguel A. Martínez-González ${ }^{a}$
}

\begin{abstract}
aDepartamento de Medicina Preventiva y Salud Pública, Universidad de Navarra, Clínica Universitaria,
Pamplona, Navarra, Spain

${ }^{b}$ Departamento de Endocrinología, Hospital de Navarra, Pamplona, Navarra, Spain

'Departamento de Fisiología y Nutrición, Universidad de Navarra, Pamplona, Navarra, Spain

dDepartamento de Medicina Preventiva y Gestión de la Calidad, Hospital Virgen del Camino, Pamplona,

Navarra, Spain
\end{abstract}

Introduction and objectives. Our aim was to investigate prospectively the association between two major cardiovascular risk factors: smoking and weight gain.

Methods. We prospectively evaluated 7565 individuals taking part in a dynamic cohort study over a median follow-up period of 50 months. Self-reported weight and physical activity levels had been validated previously. The adjusted mean difference in weight gain relative to neversmokers (the reference group) was estimated for different levels of tobacco exposure.

Results. After adjusting for age, baseline body mass index, sedentary lifestyle, changes in physical activity level, total energy intake, fiber intake, food consumption between meals, and sugary soft drink, fast food and alcohol consumption, it was found that individuals who stopped smoking during follow-up had a greater relative weight gain: men $1.63 \mathrm{~kg}$ (95\% confidence interval [Cl], $1.07-2.19 \mathrm{~kg})$, and women $1.51 \mathrm{~kg}(95 \% \mathrm{Cl}, 1.11-1.91$ $\mathrm{kg})$. In addition, active smokers had a greater weight gain than never-smokers: men $0.49 \mathrm{~kg}(95 \% \mathrm{Cl}, 0.11-0.87 \mathrm{~kg})$, and women $0.36 \mathrm{~kg}(95 \% \mathrm{Cl}, 0.07-0.65 \mathrm{~kg})$.

Conclusions. Individuals who stopped smoking during follow-up and active smokers both experienced significantly greater weight gains than never-smokers. This association between cardiovascular risk factors should be taken into account when developing prevention programs.

Key words: Epidemiology. Obesity. Smoking. Body mass index. Cohort.

This project has been subsidised by the Government of Spain (Carlos II Institute of Health, Health Projects Research Fund, projects PI030678, PI040233, PI042241, PI050514, PI050976, PI070240; PI081943; RTIC 06/0045); Department of Health of the Government of Navarra (projects $41 / 2005$ and $36 / 2008$ )

Correspondence: Dr. M. A Martínez-González.

Departamento de Medicina Preventiva. Edificio de Investigación.

Universidad de Navarra.

Irunlarrea, 1. 31080 Pamplona. Navarra. España.

E-mail: mamartinez@unav.es

Received October 3, 2008.

Accepted for publication August 21, 2009.

\section{Evolución de los cambios en el peso corporal según hábito tabáquico: análisis longitudinal de la cohorte SUN}

Introducción y objetivos. El objetivo de este estudio fue evaluar prospectivamente la asociación de dos factores de riesgo cardiovascular, el hábito tabáquico y la ganancia de peso.

Métodos. Se evaluó prospectivamente a 7.565 participantes de una cohorte dinámica durante una mediana de seguimiento de 50 meses. El peso y la actividad física declarados fueron validados previamente. Como referencia se usó a los nunca fumadores, calculándose diferencias ajustadas de ganancia media de peso para diferentes exposiciones al tabaco.

Resultados. Tras ajustar por edad, índice de masa corporal inicial, sedentarismo, cambios de actividad física, ingesta energética y de fibra, comidas entre horas, consumo de refrescos, de comida rápida y de alcohol, los participantes que dejaron de fumar durante el seguimiento, presentaron una mayor ganancia relativa de peso: hombres $+1,63 \mathrm{~kg}$ (intervalo de confianza [IC] del $95 \%, 1,07$ a 2,19); mujeres $+1,51 \mathrm{~kg}$ (IC 95\%, 1,11 a 1,91). Los fumadores activos presentaron también mayor ganancia de peso que los nunca fumadores: hombres $+0,49 \mathrm{~kg}$ (IC del 95\%, 0,11 a 0,87); mujeres +0,36 kg (IC del 95\%, 0,07 a 0,65).

Conclusiones. Los participantes que dejaron de fumar durante el seguimiento y los fumadores activos experimentaron mayores ganancias de peso que los nunca fumadores. La asociación de estos dos factores de riesgo cardiovascular debe ser tenida en cuenta en los programas de prevención.

Palabras clave: Epidemiología. Obesidad. Tabaquismo. Índice de masa corporal. Cohorte.

\section{INTRODUCTION}

After hypertension, smoking is the second largest general risk factor increasing mortality at the world level. ${ }^{1}$ It is estimated that some 1250 million people 


\section{ABBREVIATIONS}

BMI: body mass index

C_0: baseline questionnaire

C_4: 4-year follow-up questionnaire

CI: confidence interval

OR: odds ratio

SUN: University of Navarre follow-up

(Seguimiento Universidad de Navarra)

smoke in the world. ${ }^{2}$ In Spain around 150 people die each day due to smoking. ${ }^{3}$

As mortality attributable to smoking has begun to decline slightly, ${ }^{3}$ due to a reduction in the prevalence of smoking, the level of obesity has increased in Spain. ${ }^{4}$ Unfortunately, the correlation between being overweight and smoking is particularly harmful to cardiovascular health. According to the Framingham study, the life expectancy of obese smokers was at least 13 years less than non-smokers of normal weight. ${ }^{5}$

Stopping smoking has been associated with a decreased risk of cardiovascular disease and cancer. ${ }^{6}$ However, weight gain after quitting is often given as a reason for not stopping smoking, especially among women. ${ }^{6-8}$ This is increasingly well-known by the population at large and has been dealt with in clinical practice after carrying out cardiovascular prevention. Most studies have observed that there is indeed an increase in weight after stopping smoking, although the weight gain varied between them. . $9-11^{-1}$ Moreover, although of great importance, other effects that smoking has on body weight are less well known, as is the case for active smokers or exsmokers.

In Spain, long-term monitoring assessments of the correlation between these 2 major cardiovascular risk factors are scarce. ${ }^{12,13}$ The aim of our study was to assess the weight gain over time for participants in a Spanish cohort study, the SUN (Seguimiento Universidad de Navarra) cohort study, and its association with smoking.

\section{METHODS}

\section{Studied Population}

The SUN study is a dynamic prospective cohort study designed to assess the role of diet, smoking and other factors in various chronic diseases, with special emphasis on cardiovascular health. This study is within the framework of this objective. The objectives and methods of the SUN study have been the object of specific publications. ${ }^{14}$

After responding to an initial extensive questionnaire (C_0), a follow-up questionnaire has been sent to all participants every 2 years. The inclusion of participants, all university graduates, started in 1999 and is permanently open (continuous recruitment), as it was designed as a dynamic cohort study.

As of February 2008, the SUN project included 19037 participants (20\%-25\% participation rate) who completed the baseline questionnaire (C_0). ${ }^{14}$ All participants who answered the baseline questionnaire before June $2003(\mathrm{n}=11$ 707) were eligible for this analysis. We used $9294(79.4 \%)$ of those who answered the questionnaire adequately after 4 years (C_4), with a median follow-up of 50 months. The retention rate for analysis in this study, with a follow-up of only 4 years $(79.4 \%)$, is lower than the overall SUN project retention rate (>90\%); the 4-year questionnaire is the longest of all those used in the follow-up, which reduced participant response. Participants followed in the cohort study were increasingly less frequent smokers, more often married, had a lower body mass index (BMI) and were older. ${ }^{15}$ Following the recommendations for nutritional epidemiology analysis, ${ }^{16}$ participants with an extreme total calorie intake $(<800 \mathrm{kcal} /$ day for men, $<500 \mathrm{kcal} /$ day for women, or $>4000$ $\mathrm{kcal} /$ day for men and $>3500 \mathrm{kcal} /$ day for women) were excluded $(n=942)$. Of the remaining 8352 participants, 278 women were excluded because they were pregnant at the time of completing C_0 or C_4. Another 62 participants were excluded because they had extreme values for baseline BMI or BMI change during follow-up. Extreme values were considered to be those with a difference of $>3$ times the interquartile range of the 25 percentile or the 75 percentile for baseline BMI values or for the change of BMI. Finally, we excluded 324 participants who were missing data for variables related to smoking or who had inconsistent responses (a smoker in C_ 0 and never smoked in $\mathrm{C}_{-} 4$, or never smoked in $\mathrm{C}_{-} 0$ and ex-smoker in C_4). In total, data from 7565 participants were included in the analysis.

The study was approved by the Ethicas Committee of the University of Navarra. Consent for participation was assumed after voluntarily completing the baseline questionnaire (C_0).

\section{Smoking Assessment}

In C_0, participants summarised their smoking habits into three categories: never smoked, current smoker and ex-smoker. Current smokers gave their ages $(<15,15-19,20-29,30-39,40-49,50-59$, and $\geq 60$ 
years) and the number of cigarettes (1-4, 5-14, 15-24, 25-34, 35-44, and >45); while ex-smokers specified the amount of time since stopping smoking $(<1,1-2$, $3-5,6-9$, and $>10$ years). The baseline questionnaire also asked if the participant smoked a pipe or cigars.

C_4 again classified participants into the same three categories: never smoked, current smoker and ex-smoker. Current smokers said since when, and the number of cigarettes, they smoked (as with C_0); and ex-smokers specified the amount of time since stopping smoking (as with C_0).

Participants who reported never smoking in both C_0 and C_4 were included in the group of people who had never smoked. Participants who declared themselves to be ex-smokers in $\mathrm{C}_{-} 0$ and either ex-smokers or having never smoked in $\mathrm{C}_{-} 4$ were considered to be ex-smokers. Participants who were smokers in C_4 but who had never smoked in C_0 were considered to have started smoking. Participants in C_4 who were active smokers and ex-smokers or active smokers in $\mathrm{C}_{-} 0$ were included in the group of active smokers. Declared ex-smokers in C_4 who were smokers in C_0 were included in the group of participants who had stopped smoking.

\section{Assessment of Other Variables}

Eating habits in the baseline questionnaire were evaluated by food intake frequency (of 136 items), which had been previously validated in Spain. ${ }^{17}$ Total fibre intake, alcohol, fast food (hamburgers, pizza, and sausages) and sugary, soft drinks were estimated from semi-quantitative food frequency questionnaires, by applying the average size of the ration given in the questionnaire to each frequency (9 categories from "never or almost never" to " 6 or more times a day"). This was adjusted for total energy (residual method). ${ }^{18}$

Physical inactivity was assessed by multiplying the number of hours sitting down on a typical working day by 5 , then adding the average estimate for a typical weekend day multiplied by 2 .

Baseline physical activity during leisure time was assessed through questions on participation in 17 different activities. This estimate had been previously validated by finding a good correlation (Spearman's rho $\rho=+0.51, P<.001$ ) with energy expended, objectively measured in a subsample of the cohort study. ${ }^{19}$

Changes in physical activity were evaluated in C_4 using a qualitative variable that classified participants into three possible categories: those who had not changed physical exercise since C_0, those who had increased it and those who had decreased it.

\section{Weight Gain Assessment}

The declared weights were collected from participants in C_0 and C_4. The follow-up questionnaire (C_4) was completed at least four years after the baseline questionnaire. The median followup was 50 months (mean [SD], 50.2 [4.6] months). Weight was previously validated in a subsample of the cohort study. A small mean relative error $(1.45 \%)$ was found, and a Pearson correlation coefficient between measured and declared weight of $0.99(95 \%$ confidence interval [ $95 \% \mathrm{CI}], 0.98-0.99){ }^{20}$

The dependent variables were body weight gain during follow-up (continuous variable: $\mathrm{C}_{-} 4$ weight minus C_0 weight, in $\mathrm{kg}$ ) and any weight gain $\geq 5 \mathrm{~kg}$ at follow-up (dichotomous variable).

\section{Statistical Analysis}

Multiple regression models were used to assess the association between the different smoking categories and weight gain during follow-up, with the category of people who had never smoked as the reference. Therefore, their results show the average difference in weight gain for each smoker category compared to those who had never smoked.

Unconditional logistic regression models were used to assess the relationship between different categories of smokers and the risk of gaining $\geq 5 \mathrm{~kg}$ at follow-up.

For both linear and logistic models, a crude model was first calculated followed by a multivariate one adjusted for age (continuous), baseline BMI (continuous), physical inactivity (tertiles), physical exercise during follow-up (increasing, unchanged or decreasing), total energy intake (continuous), habit of eating between meals ("snacking"), sugary drink consumption (tertiles), ${ }^{21}$ total dietary fibre intake (continuous), consumption of fast food (tertiles), ${ }^{21}$ and alcohol consumption (tertiles).

All models were prepared separately for men and women. All $P$ values shown are 2-tailed, and a $P<.05$ value was considered a priori as statistically significant.

\section{RESULTS}

The baseline average weight (standard deviation) was 77.9 (10.2) $\mathrm{kg}$ for men and $58.3(7.8) \mathrm{kg}$ for women. The mean baseline BMI was $25.2(2.9) \mathrm{kg} \mathrm{m}^{-2}$ for men and $21.8(2.7) \mathrm{kg} \mathrm{m}^{-2}$ for women. After the follow-up (median of 50 months), the mean weight gain was $1.03(4.12) \mathrm{kg}$ for men and $1.22(3.66) \mathrm{kg}$ for women.

Table 1 shows the baseline characteristics of participants by smoking category. Table 2 shows the baseline BMI and age of smokers according to 


\begin{tabular}{|c|c|c|c|c|c|c|}
\hline & $\begin{array}{l}\text { Never } \\
\text { Smoked }\end{array}$ & $\begin{array}{l}\text { Ex-Smokers at } \\
\text { C_0 and C_4 }\end{array}$ & $\begin{array}{l}\text { Stopped } \\
\text { Smoking }\end{array}$ & $\begin{array}{c}\text { Started } \\
\text { Smoking }\end{array}$ & $\begin{array}{l}\text { Active Smokers } \\
\text { at C_0 and C_4 }\end{array}$ & Total \\
\hline \multicolumn{7}{|l|}{ Men } \\
\hline Sample size & 1438 & 927 & 239 & 25 & 639 & 3268 \\
\hline Age, y & $38.0(12.3)$ & $49.2(11.7)$ & $41.0(12.7)$ & $37.7(13.4)$ & $40.1(11.9)$ & $41.8(13)$ \\
\hline Weight, kg & $76.7(9.9)$ & $79.0(10.2)$ & $78.8(9.4)$ & $76.4(9)$ & $78.9(11.1)$ & $77.9(10.2)$ \\
\hline BMI, $\mathrm{kg} / \mathrm{m}-2$ & $24.7(2.7)$ & $26.0(2.8)$ & $25.5(3)$ & $24.9(2.7)$ & $25.3(3)$ & $25.2(2.9)$ \\
\hline Snacking (yes) & $29.1 \%$ & $22.9 \%$ & $25.4 \%$ & $41.7 \%$ & $28.9 \%$ & $27.1 \%$ \\
\hline Sugary drinks (upper tertile) & $30.3 \%$ & $17.7 \%$ & $38.5 \%$ & $24.0 \%$ & $35.4 \%$ & $28.2 \%$ \\
\hline Fast food (upper tertile) & $32.1 \%$ & $21.3 \%$ & $31.0 \%$ & $36.0 \%$ & $34.0 \%$ & $29.3 \%$ \\
\hline Hours seated (upper tertile) & $29.8 \%$ & $31.2 \%$ & $28.8 \%$ & $17.6 \%$ & $34.6 \%$ & $31 \%$ \\
\hline Alcohol (upper tertile) & $22.9 \%$ & $36.9 \%$ & $40.6 \%$ & $36.0 \%$ & $47.3 \%$ & $33.0 \%$ \\
\hline Total fibre intake, g day-1 & $26(12)$ & $27(12)$ & $24(10)$ & $27(10)$ & $24(10)$ & $26(11)$ \\
\hline Total energy, kcal day -1 & $2510(654)$ & $2334(654)$ & $2470(709)$ & $2543(661)$ & $2482(672)$ & $2452(666)$ \\
\hline Baseline physical activity, h/week & $30.2(26.8)$ & $25.9(22.6)$ & $24.5(20.2)$ & $27.3(28.3)$ & $24.7(23)$ & $27.4(24.6)$ \\
\hline Increased physical activity during follow-up & $10.9 \%$ & $12.0 \%$ & $10.0 \%$ & $12.0 \%$ & $8.5 \%$ & $10.7 \%$ \\
\hline \multicolumn{7}{|l|}{ Women } \\
\hline Sample size & 2130 & 880 & 375 & 42 & 870 & 4297 \\
\hline Age, y & $33.5(10.8)$ & $40.1(9.7)$ & $32.5(8.7)$ & $27.4(10.2)$ & $33.4(10)$ & $34.7(10.6)$ \\
\hline Weight, $\mathrm{kg}$ & $57.9(7.7)$ & $58.9(7.7)$ & $58.3(8.4)$ & $59.5(9)$ & $58.6(7.9)$ & $58.3(7.8)$ \\
\hline BMI, kg m-2 & $21.7(2.6)$ & $22.3(2.7)$ & $21.6(2.6)$ & $21.6(2.7)$ & $21.8(2.7)$ & $21.8(2.7)$ \\
\hline Snacking (yes) & $38.6 \%$ & $32.6 \%$ & $41.8 \%$ & $59.5 \%$ & $40.2 \%$ & $38.2 \%$ \\
\hline Sugary drinks (upper tertile) & $19.8 \%$ & $15.1 \%$ & $26.4 \%$ & $40.5 \%$ & $27.5 \%$ & $21.2 \%$ \\
\hline Fast food (upper tertile) & $38.6 \%$ & $30.5 \%$ & $44.0 \%$ & $28.6 \%$ & $37.7 \%$ & $37.1 \%$ \\
\hline Hours seated (upper tertile) & $35.5 \%$ & $28.5 \%$ & $36.0 \%$ & $44.8 \%$ & $37.3 \%$ & $34.3 \%$ \\
\hline Alcohol (upper tertile) & $24.8 \%$ & $39.3 \%$ & $45.3 \%$ & $31.0 \%$ & $41.7 \%$ & $33.0 \%$ \\
\hline Total fibre intake, g/day-1 & $28(12)$ & $29(12)$ & $26(12)$ & $25(9)$ & $26(11)$ & $27(11.9)$ \\
\hline Total energy, kcal/day-1 & $2338(571)$ & $2264(588)$ & $2294(600)$ & $2244(703)$ & $2289(583)$ & $2308(581)$ \\
\hline Baseline physical activity, h/week & $22.4(18.2)$ & $20.9(17)$ & $20.7(17.3)$ & $27.9(23.4)$ & $19.5(16.1)$ & $21.4(17.6)$ \\
\hline Increased physical activity during follow-up & $13.4 \%$ & $14.3 \%$ & $14.4 \%$ & $23.8 \%$ & $15.9 \%$ & 14.3 \\
\hline
\end{tabular}

$\mathrm{C} 0$ indicates baseline questionnaire, $\mathrm{C} 4$, follow-up questionnaire at 4 years (50 months); BMI, body mass index.

Shows the mean (standard deviation) unless specified otherwise.

the number of cigarettes smoked at the start of the study. Participants who smoked more cigarettes at baseline had a significantly higher BMI at the start of the study.

The weight gain in participants who had never smoked was on average: +0.95 (3.99) $\mathrm{kg}$ in men and +0.95 (3.53) $\mathrm{kg}$ in females. Using participants who had never smoked as a reference, and adjusting for potential confusors, participants who stopped smoking during follow-up had a greater weight gain: $+1.63 \mathrm{~kg}(95 \% \mathrm{CI}, 1.07-2.19 \mathrm{~kg})$ for men and +1.51 $\mathrm{kg}$ (1.11-1.91) for women (Table 3). This equates to an increase in baseline weight of $2.1 \%(1.4 \%-2.8 \%)$ in men and $2.6 \%(1.9 \%-3.3 \%)$ in women, compared to those who had never smoked. Active smokers also had a higher weight gain during follow up when compared to people who had never smoked: +0.49 $\mathrm{kg}(0.11-0.87)$ for men and $+0.36 \mathrm{~kg}(0.07-0.65)$ for women. Men who were ex-smokers at baseline did not have a significant increase in weight at followup: $+0.22 \mathrm{~kg}(-0.14$ to 0.57$)$. However, women who were ex-smokers showed a significant increase over those who had never smoked $+0.39 \mathrm{~kg}(0.10-0.68)$. Participants who had started smoking were not significantly different from non-smokers, although in women the point estimate of the difference was negative.

When a multivariate adjustment was applied to assess weight change in participants who had stopped smoking at the follow-up, using the baseline smoking categories (1-4, 5-14 cigarettes a day, etc), it was noted that going up a category involved a weight gain of $+1.16 \mathrm{~kg}(0.50-1.82)$ for men and $+0.81 \mathrm{~kg}(0.30-1.33)$ for women.

In assessing the weight gain of participants who continued smoking at follow-up, according to baseline smoking categories, there was no difference between the different categories after adjusting for potential confusion variables. The increase in a category gave a weight gain difference of $+0.13 \mathrm{~kg}$ $(-0.22-0.48)$ for men and $+0.04 \mathrm{~kg}(-0.23-0.31)$ for women.

Furthermore, when comparing the weight gain of participants who stopped smoking to those who 
TABLE 2. Smokers' BMI Distribution at Baseline, According to the Number of Cigarettes

\begin{tabular}{|c|c|c|c|c|c|c|c|c|}
\hline \multicolumn{9}{|c|}{ Baseline Smoking Habit } \\
\hline & 1-4 Cigarettes & 5-14 Cigarettes & 15-24 Cigarettes & 25-34 Cigarettes & 35-44 Cigarettes & $>45$ Cigarettes & $\mathbf{p a}^{\mathrm{a}}$ & $\mathbf{P b}^{b}$ \\
\hline \multicolumn{9}{|l|}{ Men } \\
\hline Sample size & 158 & 196 & 246 & 49 & 21 & 4 & & \\
\hline Age, y & $40.9(12.6)$ & $37.9(11.7)$ & $36.9(11.6)$ & $41.5(10.1)$ & $43.9(10.8)$ & $50.6(13)$ & & \\
\hline $\mathrm{BMI}, \mathrm{kg} / \mathrm{m}^{-2}$ & $24.7(2.4)$ & $24.8(2.9)$ & $25.4(3.1)$ & $26.0(3.4)$ & $26.3(2.9)$ & $26.4(3.4)$ & .007 & .003 \\
\hline \multicolumn{9}{|l|}{ Women } \\
\hline Sample size & 304 & 413 & 262 & 34 & 22 & 4 & & \\
\hline Age, y & $32.4(9.1)$ & $32.0(9.6)$ & $32.6(9.6)$ & $36.0(8.7)$ & $39.9(7.6)$ & $32.8(11.6)$ & & \\
\hline $\mathrm{BMI}, \mathrm{kg} / \mathrm{m}^{-2}$ & $21.4(2.5)$ & $21.7(2.5)$ & $21.7(2.8)$ & $22.7(3.5)$ & $23.3(3.6)$ & $22.8(1.8)$ & .001 & .002 \\
\hline
\end{tabular}

$\mathrm{BMI}$ indicates body mass index.

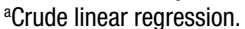

${ }^{\mathrm{b}}$ Multivariate linear regression: data adjusted for age (continuous) snacking (yes/no), sugary drinks consumption (tertiles), total energy (continuous), hours seated (tertiles), total fibre (continuous), fast food (tertiles), alcohol (tertiles).

'No information was available about the number of cigarettes smoked for 204 men and 206 women smokers in the baseline questionnaire.

Shows the mean (standard deviation).

\begin{tabular}{|c|c|c|c|c|c|c|c|}
\hline & No. & $\begin{array}{l}\text { Weight Change } \\
\text { (Crude Estimate) }\end{array}$ & $P$ & $\begin{array}{l}\text { Age-Adjusted Relative } \\
\text { Difference }(95 \% \mathrm{Cl})\end{array}$ & $P$ & $\begin{array}{l}\text { Multivariable Adjusted Relative } \\
\text { Difference }(95 \% \text { CI) }\end{array}$ & $P$ \\
\hline \multicolumn{8}{|l|}{ Men } \\
\hline Never smoked & 1438 & $0.95(3.99)$ & & 0 (ref) & & 0 (ref) & \\
\hline Ex-smokers in $\mathrm{CO}$ and $\mathrm{C} 4$ & 927 & $0.57(3.91)$ & .009 & $0.11(-0.24$ to 0.46$)$ & .53 & $0.22(-0.14$ to 0.57$)$ & .23 \\
\hline Stopped smoking & 239 & $2.31(5.09)$ & $<.001$ & $1.41(0.86$ to 1.96$)$ & $<.001$ & 1.63 (1.07 to 2.19$)$ & $<.001$ \\
\hline Started smoking & 25 & $1.36(4.18)$ & 0.68 & $0.29(-1.31$ to 1.90$)$ & .72 & $0.22(-1.40$ to 1.85$)$ & .79 \\
\hline Active smokers & 639 & $1.41(4.23)$ & .04 & 0.47 (0.09 to 0.84$)$ & .01 & $0.49(0.11$ to 0.87$)$ & .01 \\
\hline \multicolumn{8}{|l|}{ WOMEN } \\
\hline Never smoked & 2130 & $0.95(3.53)$ & & 0 (ref) & & 0 (ref) & \\
\hline Ex-smokers in $\mathrm{CO}$ and $\mathrm{C} 4$ & 880 & $1.30(3.52)$ & .03 & 0.40 (0.11 to 0.69$)$ & .008 & $0.39(0.10$ to 0.68$)$ & .009 \\
\hline Stopped smoking & 375 & $2.48(4.26)$ & $<.001$ & 1.49 (1.10 to 1.89$)$ & $<.001$ & 1.51 (1.11 to 1.91$)$ & $<.001$ \\
\hline Started smoking & 42 & $0.67(4.29)$ & .59 & $-0.38(-1.49$ to 0.74$)$ & .51 & $-0.32(-1.42$ to 0.79$)$ & .57 \\
\hline Active smokers & 870 & $1.29(3.72)$ & .03 & 0.31 (0.02 to 0.59$)$ & .03 & 0.36 (0.07 to 0.65$)$ & .01 \\
\hline
\end{tabular}

C0 indicates baseline questionnaire; C4, 4-year follow-up questionnaire (50 months); SD, standard deviation; Cl, confidence interval.

Data adjusted for age (continuous), snacking (yes/no), sugary drinks consumption (tertiles), total energy (continuous), hours seated (tertiles), physical exercise at follow-up (increase, no change, decrease), total fibre (continuous) fast food (tertiles), alcohol (tertiles), and baseline body mass index (continuous). aMean (SD).

were still smoking, an adjusted difference in weight gain of $+1.08 \mathrm{~kg}(0.40-1.76)$ was obtained for men, and $+1.17 \mathrm{~kg}(0.69-1.64)$ for women.

When a multivariate model was used to evaluate differences in weight gain for participants who were ex-smokers in C_0, who had stopped smoking within a year of completing the C_0 questionnaire, a non-significant difference in weight gain of +0.63 $\mathrm{kg}(-0.26$ to 1.52$)$, was found for men. However, for women a significant difference in weight gain of $+0.77 \mathrm{~kg}(0.04-1.50)$ was found.

Furthermore, using the participants who had never smoked as reference, men and women who had stopped smoking at follow-up had a statistically significant probability of gaining $\geq 5 \mathrm{~kg}$ in body weight: the adjusted odds ratio (OR) was 2.53 (1.83-
3.50) for men and 3.08 (2.35-4.03) for women (Table 4). In addition, participants who were smokers at baseline and continued to smoke were also more likely than people who had never smoked to gain 5 $\mathrm{kg}$ or more: $\mathrm{OR}=1.31$ (1.02-1.68) for men, 1.70 (1.352.13) for women. Ex-smoking women, but not men, at baseline were more likely to gain $5 \mathrm{~kg}$ or more during follow-up: OR 1.32 (1.03-1.69).

\section{DISCUSSION}

In this prospective study, men and women who smoked at baseline gained weight during the study, and this was more marked for those who had stopped smoking at the follow-up period. This weight gain in participants who had stopped smoking was greater 
TABLE 4. Odds Ratios (OR) and $\mathbf{9 5 \%}$ Confidence Intervals (Cl) for Gaining $\geq \mathbf{5}$ kg After $\mathbf{5 0}$ Months Follow-up in the SUN Study

\begin{tabular}{|c|c|c|c|c|c|c|c|}
\hline & No. & OR (95\% Cl) & $P$ & $\begin{array}{l}\text { OR Age-Adjusted } \\
\quad(95 \% \mathrm{Cl})\end{array}$ & $P$ & $\begin{array}{l}\text { OR, Multivariable Adjusted } \\
\qquad(95 \% \mathrm{CI})^{\mathrm{a}}\end{array}$ & $P$ \\
\hline \multicolumn{8}{|l|}{ Men } \\
\hline Never smoked & 1438 & 1 (ref) & & 1 (ref) & & 1 (ref) & \\
\hline Ex-smokers in $\mathrm{C} 0$ and $\mathrm{C} 4$ & 927 & 0.67 (0.53 to 0.85$)$ & .001 & 1.03 (0.80 to 1.34$)$ & .81 & 1.05 (0.80 to 1.36$)$ & .74 \\
\hline Stopped smoking & 239 & 2.13 (1.57 to 2.90$)$ & $<.001$ & 2.40 (1.75 to 3.29$)$ & $<.001$ & 2.53 (1.83 to 3.50$)$ & $<.001$ \\
\hline Started smoking & 25 & 1.26 (0.47 to 3.39$)$ & .65 & 1.21 (0.44 to 3.31$)$ & .71 & 1.19 (0.42 to 3.32$)$ & .75 \\
\hline Active smokers & 639 & 1.23 (0.97 to 1.55$)$ & .09 & 1.31 (1.03 to 1.67$)$ & .03 & 1.31 (1.02 to 1.68$)$ & .04 \\
\hline Women & 2130 & 1 (ref) & & 1 (ref) & & 1 (ref) & \\
\hline Never smoked & 880 & 1.16 (0.92 to 1.46$)$ & .21 & 1.28 (1.01 to 1.62$)$ & .04 & 1.32 (1.03 to 1.69$)$ & .03 \\
\hline Ex-smokers in $\mathrm{C} 0$ and $\mathrm{C} 4$ & 375 & 2.92 (2.25 to 3.78$)$ & $<.001$ & 2.89 (2.23 to 3.74$)$ & $<.001$ & 3.08 (2.35 to 4.03$)$ & $<.001$ \\
\hline Stopped smoking & 42 & 1.76 (0.81 to 3.85$)$ & .15 & 1.62 (0.74 to 3.55$)$ & .23 & $1.58(0.71$ to 3.51$)$ & .26 \\
\hline Started smoking & 870 & 1.60 (1.29 to 1.99$)$ & $<.001$ & 1.60 (1.29 to 1.99$)$ & $<.001$ & 1.70 (1.35 to 2.13$)$ & $<.001$ \\
\hline
\end{tabular}

$\mathrm{CO}$ indicates baseline questionnaire; $\mathrm{C4}$, 4-year follow-up questionnaire (50 months); $\mathrm{Cl}$, confidence interval; OR, odds ratio.

aData adjusted for age (continuous), snacking (yes/no), sugary drinks consumption (tertiles), total energy (continuous), hours seated (tertiles), physical exercise at follow-up (increase, no change, decrease), total fibre (continuous) fast food (tertiles), alcohol (tertiles), and baseline body mass index (continuous).

the more cigarettes they used to smoke per day when entering the cohort study. Women who stopped smoking before the baseline questionnaire also showed a greater weight gain at follow-up, when compared with women who had never smoked.

In a cohort study with 10 years of follow-up, Williamson et $\mathrm{al}^{11}$ also found that men gained on average $2.8 \mathrm{~kg}$ in weight after stopping smoking, while women gained $3.8 \mathrm{~kg}$. Several studies have shown a weight gain after quitting smoking, although the size of this increase varies from one study to another., ${ }^{7,22}$ In our cohort study, participants who smoked more at baseline had a higher weight gain after stopping. This agrees with results from other studies. ${ }^{11,23}$ Some studies have found that younger participants gain more weight. ${ }^{10,11,24}$ However, our study found no significant age differences for weight gain associated with stopping smoking (data not shown). Other studies have found that black people ${ }^{11}$ or those of a lower socioeconomic class ${ }^{24}$ gain more weight after stopping smoking. This phenomenon may have meant that the weight gain in our cohort study was somewhat lower, as the SUN study is composed of Spanish university graduates. ${ }^{14}$

Ex-smokers at baseline in our cohort study, who had stopped smoking within one year of filling out the baseline questionnaire had greater weight gain at follow-up than those who stopped smoking sooner. This greater weight gain at follow-up was significant only in women, however. These data are consistent with studies indicating that much of the weight gain that occurs after stopping smoking occurs within the first year of doing so. ${ }^{10}$

Our study found no significantly higher weight gain in participants who began smoking compared with those who had never smoked, although the number of participants who began smoking during follow-up was small. In the literature, some prospective studies found a lower weight gain among participants who started smoking, ${ }^{25}$ others found a lower gain in black people but no differences for white people, ${ }^{26}$ while others found a higher gain in participants who started smoking. ${ }^{27}$

In our study, participants who smoked at baseline and were still smoking at follow-up had a greater weight gain than those who had never smoked; a finding consistent with an American nurses cohort study ${ }^{27}$ It was also noted that both men and women who smoked more at baseline had a higher BMI in the questionnaire than those who smoked less. This is consistent with other cross-sectional studies that suggest an important correlation between the two factors with serious implications for the future of a cardiovascular epidemic. ${ }^{28,29}$ The reason for this increased weight gain is not well known, but may be related to the fact that heavy smokers may have other lifestyle habits that promote weight gain. In fact, a previous study in young men in Spain found that subjects who had smoked had a poor BMI development. ${ }^{13}$ However, despite the correlation found in the baseline questionnaire, and although smokers at follow-up gained significantly more weight than those who had never smoked, we found no clear association between the number of cigarettes smoked at baseline and weight gain at follow-up, unlike that observed in the nurse cohort study. ${ }^{27}$

Participants who had stopped smoking at followup and those who continued smoking had a greater weight gain with respect to people who had never smoked. This greater weight gain was significant after adjusting for other confusor variables, which could provide alternative explanations for the greater 
gain in weight. Admittedly, that residual confusion may explain this phenomenon, but perhaps the fact that smokers are less health-conscious and may have less willpower in health matters than those who have never smoked may make them more vulnerable to a greater gain in weight. ${ }^{30}$ Because any inattention to health matters is difficult to measure in a questionnaire, it might partly explain our results.

There was no control over socioeconomic status, and to control any confusion due to socioeconomic level, all participants in this study are university graduates. In addition, multivariate models were adjusted for changes in the level of physical activity during follow-up rather than baseline physical activity, since previous work in this very cohort study $^{31}$ found that what matters, in explaining any weight changes in participants during follow up, was the change in physical exercise at follow-up, and not the physical activity at baseline. When further adjusted for baseline physical activity, the results barely changed.

One possible limitation of the study is that the weight data used was provided by the participants themselves. The validity of weight information provided in this way was studied in a representative sample of the cohort study, which revealed a mean relative error of $1.45 \%$ in the declared weights. ${ }^{20}$ In any case, the fact of using self-declared data may attenuate the relationship between smoking and participant weight.

The SUN study is not representative of the population in general as it is composed exclusively of Spanish university graduates, where a higher cultural level has been associated with a lower prevalence of obesity. ${ }^{4} \mathrm{We}$ recognise this lack of representativeness, which prevents the absolute values of weight gain observed from being accepted as definitive. However, it seems biologically implausible that the effect of smoking on weight gain can be modified by educational level, and therefore there is no reason to believe that the results observed are not valid. ${ }^{32}$ Moreover, the study has some strengths, such as the prospective design, the prolonged follow-up time and the availability of validation studies.

\section{CONCLUSIONS}

Smoking is not an effective way to prevent obesity, and in fact increases it, especially among ex-smokers and smokers who continue their habit. Essential prevention of smoking would also help to prevent the correlation between these two cardiovascular risk factors, at least in middle-aged adults of a high educational level. Future studies with a longer follow-up period, with participants from other socioeconomic and educational backgrounds, will help to confirm and extrapolate these results to other sectors of the population.

\section{ACKNOWLEDGMENTS}

We are grateful for the cooperation and continued participation of the SUN cohort participants. We would also like to thank other members of the SUN study: C de la Fuente, Z Vázquez, S Benito, M SeguíGómez, J de Irala, A Marti, F Guillen-Grima, M Serrano-Martínez, E Toledo, EH Martinez de la Piscina from the University of Navarra; M DelgadoRodríguez from the University of Jaén; J Llorca, at the University of Cantabria; and A Sanchez-Villegas, at the University of Las Palmas. We are also grateful to the members of the Department of Nutrition, Harvard School of Public Health (A Ascherio, FB Hu, and WC Willett) who helped us design the SUN study.

\section{REFERENCES}

1. Lopez AD, Mathers CD, Ezzati M, Jamison DT, Murray CJ. Global and regional burden of disease and risk factors, 2001: systematic analysis of population health data. Lancet. 2006;367:1747-57.

2. Mackay J EM. The Tobacco Atlas. Ginebra: OMS, 2002. Available from: http://whqlibdoc.who.int/publications/ 2002/9241562099.pdf (Accessed Sep 12, 2008).

3. Banegas JR, Diez Ganan L, Gonzalez Enriquez J, Villar Alvarez F, Rodriguez-Artalejo F. La mortalidad atribuible al tabaquismo comienza a descencer en España. Med Clin (Barc). 2005;124:769-71.

4. Basterra-Gortari FJ, Bes-Rastrollo M, Segui-Gomez M, Forga L, Martinez JA, Martinez-Gonzalez MA. Tendencias de la obesidad, diabetes mellitus, hipertensión e hipercolesterolemia en España (1997-2003). Med Clin (Barc). 2007;129:405-8.

5. Peeters A, Barendregt JJ, Willekens F, Mackenbach JP, Al Mamun A, Bonneux L. Obesity in adulthood and its consequences for life expectancy: a life-table analysis. Ann Intern Med. 2003;138:24-32.

6. US Department of Health and Human Services. The health benefits of smoking cessation. Rockville, MD: Office on Smoking and Health, Center for Chronic Disease Prevention and Health Promotion, Centers for Disease Control, Public Health Service, US Department of Health and Human Services, 1990. (DHHS publication no. (CDC) 90-8416). Available fom: http://profiles.nlm.nih.gov/NN/B/B/C/T/_/nnbbct.pdf (Accessed Sep 12, 2008).

7. Klesges RC, Brown K, Pascale RW, Murphy M, Williams E, Cigrang JA. Factors associated with participation, attrition, and outcome in a smoking cessation program at the workplace. Health Psychol. 1988;7:575-89.

8. Pomerleau CS, Zucker AN, Stewart AJ. Characterizing concerns about post-cessation weight gain: results from a national survey of women smokers. Nicotine Tob Res. 2001;3:51-60.

9. Klesges RC, Meyers AW, Klesges LM, La Vasque ME. Smoking, body weight, and their effects on smoking behavior: a comprehensive review of the literature. Psychol Bull. 1989;106:204-30.

10. O'Hara P, Connett JE, Lee WW, Nides M, Murray R, Wise R. Early and late weight gain following smoking cessation in the Lung Health Study. Am J Epidemiol. 1998;148:821-30.

11. Williamson DF, Madans J, Anda RF, Kleinman JC, Giovino GA, Byers T. Smoking cessation and severity of weight gain in a national cohort. N Engl J Med. 1991;324:739-45.

12. Becona E, Vazquez FL. Smoking cessation and weight gain in smokers participating in a behavioral treatment at 3-year follow-up. Psychol Rep. 1998;82:999-1005. 
13. Laclaustra-Gimeno M, Gonzalez-Garcia MP, CasasnovasLenguas JA, Luengo-Fernandez E, Leon-Latre M, PorteroPerez P, et al. Evolución de los factores de riesgo cardiovascular en jóvenes varones tras 15 años de seguimiento en el estudio Academia General Militar de Zaragoza (AGEMZA). Rev Esp Cardiol. 2006;59:671-8.

14. Segui-Gomez M, de la Fuente C, Vazquez Z, de Irala J, Martinez-Gonzalez MA. Cohort profile: the 'Seguimiento Universidad de Navarra' (SUN) study. Int J Epidemiol. 2006; $35: 1417-22$.

15. Alonso A, Segui-Gomez M, de Irala J, Sanchez-Villegas A, Beunza JJ, Martinez-Gonzalez MA. Predictors of follow-up and assessment of selection bias from dropouts using inverse probability weighting in a cohort of university graduates. Eur J Epidemiol. 2006;21:351-8.

16. Willett WC. Issues in analysis and presentation of dietary data. En: Willett WC. Nutritional epidemiology. 2nd ed. New York: Oxford University Press; 1998:321-46.

17. Martin-Moreno JM, Boyle P, Gorgojo L, Maisonneuve P, Fernandez-Rodriguez JC, Salvini S, et al. Development and validation of a food frequency questionnaire in Spain. Int $\mathbf{J}$ Epidemiol. 1993;22:512-9.

18. Willett WC, Stampfer MJ. Implications of total energy intake for epidemiologic analyses. En: Willett WC. Nutritional epidemiology. 2nd ed. New York: Oxford University Press; 1998:273-301.

19. Martinez-Gonzalez MA, Lopez-Fontana C, Varo JJ, SanchezVillegas A, Martinez JA. Validation of the Spanish version of the physical activity questionnaire used in the Nurses' Health Study and the Health Professionals' Follow-up Study. Public Health Nutr. 2005;8:920-7.

20. Bes-Rastrollo M, Perez JR, Sánchez-Villegas A, Alonso A, Martínez-González MA. Validación del peso e índice de masa corporal auto-declarado de los participantes de una cohorte de graduados universitarios. Rev Esp Obes. 2005;3:352-8.

21. Bes-Rastrollo M, Sanchez-Villegas A, Gomez-Gracia E, Martinez JA, Pajares RM, Martinez-Gonzalez MA. Predictors of weight gain in a Mediterranean cohort: the Seguimiento
Universidad de Navarra Study 1. Am J Clin Nutr. 2006;83:36270; quiz 394-5.

22. Filozof C, Fernandez Pinilla MC, Fernandez-Cruz A. Smoking cessation and weight gain. Obes Rev. 2004;5:95-103.

23. John U, Meyer C, Rumpf HJ, Schumann A, Dilling H, Hapke $\mathrm{U}$. No considerable long-term weight gain after smoking cessation: evidence from a prospective study. Eur J Cancer Prev. 2005; 14:289-95.

24. Swan GE, Carmelli D. Characteristics associated with excessive weight gain after smoking cessation in men. Am J Public Health. 1995;85:73-7.

25. Shimokata H, Muller DC, Andres R. Studies in the distribution of body fat. III. Effects of cigarette smoking. JAMA. 1989;261:1169-73.

26. Klesges RC, Ward KD, Ray JW, Cutter G, Jacobs DR, Jr., Wagenknecht LE. The prospective relationships between smoking and weight in a young, biracial cohort: the Coronary Artery Risk Development in Young Adults Study. J Consult Clin Psychol. 1998;66:987-93.

27. Colditz GA SM, Myers AH, Stampfer MJ, Willett W, Speizer FE. Weight change in relation to smoking cessation in women. J Smoking Relat Dis. 1992;3:145-53.

28. Chiolero A, Jacot-Sadowski I, Faeh D, Paccaud F, Cornuz J. Association of cigarettes smoked daily with obesity in a general adult population. Obesity (Silver Spring). 2007;15:1311-8.

29. Rasky E, Stronegger WJ, Freidl W. The relationship between body weight and patterns of smoking in women and men. Int $\mathbf{J}$ Epidemiol. 1996;25:1208-12.

30. Martinez-Gonzalez MA, de Irala J. Medicina preventiva y fracaso clamoroso de la salud pública: llegamos mal porque llegamos tarde Med Clin (Barc). 2005;124:656-60.

31. Basterra-Gortari FJ, Bes-Rastrollo M, Pardo-Fernandez M, Forga L, Martinez JA, Martinez-Gonzalez MA. Changes in weight and physical activity over two years in Spanish alumni. Med Sci Sports Exerc. 2009;41:516-22.

32. Rothman KJ GS. Precision and validity in epidemiologic studies. In: Rothman, Greenland S, eds. Modern Epidemiology. 2nd ed. Philadelphia, PA: Lippincott-Raven: 1998. p. 115-34. 